\title{
Synergistic effect of anethole on the activity of abamectin against the lesser mealworm (Alphitobius diaperinus Panzer)
}

\section{Synergistyczny wpływ anetolu na aktywność abamektyny wobec pleśniakowca Iśniącego (Alphitobius diaperinus Panzer)}

\author{
Maryla Szczepanik $^{1 *}$, Paulina Orszewska ${ }^{2}$, Beata Szołyga ${ }^{1}$
}

\begin{abstract}
Summary
The synergistic effect of anethole, the main component of star anise oil, on the activity of abamectin (Vertimec $018 \mathrm{EC}$ ) against the lesser mealworm (Alphitobius diaperinus Panzer) was investigated. In the studies $1 \%$ acetone solutions of anethole and aqueous solutions of insecticide with increasing concentrations $(0.0125 ; 0.025 ; 0.05 ; 0.1 ; 0.15 ; 0.2 ; 0.4 \%)$ were used. The experiments were conducted on 10-day and 20-day old larvae and young (7-10 day old) adults using an oral administration of compounds in four different treatments (insecticide alone, anethole alone, insecticide given simultaneously with anethole, insecticide application was preceded by a 3-day culture on diet treated with anethole). The experiments were carried out in the rearing chamber at $29^{\circ} \mathrm{C}$ in the dark. The results show that anethole have a synergistic effect on the activity of abamectin only against the youngest larvae. After the simultaneous application of anethole and insecticide more than 4-fold decrease in the values of $\mathrm{LC}_{50}$ and $\mathrm{LC}_{90}$ was observed. In relation to older larvae and adults synergistic activity of anethole was very weak. Synergism ratios were 1.05-1.26.
\end{abstract}

Key words: abamectin; anethole; synergism; essential oils; lesser mealworm; Alphitobius diaperinus

\section{Streszczenie}

Zbadano synergistyczny wpływ anetolu, głównego składnika olejku anyżowego, na toksyczność abamektyny (s.cz. insektycydu Vertimec $018 \mathrm{EC}$ ) na przykładzie pleśniakowca lśniącego (Alphitobius diaperinus Panzer). W badaniach zastosowano $1 \%$ acetonowe roztwory anetolu oraz wodne roztwory insektycydu o wzrastających stężeniach: 0,$0125 ; 0,025 ; 0,05 ; 0,1 ; 0,15 ; 0,2 ; 0,4 \%$. Doświadczenia prowadzono na 10- i 20-dniowych larwach oraz młodych (7-10 dniowych) chrząszczach $A$. diaperinus, stosując metodę żołądkową w 4 różnych kombinacjach (insektycyd, anetol, insektycyd aplikowany jednocześnie z anetolem, aplikacja insektycydu poprzedzona 3-dniową hodowlą owadów na pokarmie traktowanym anetolem). Doświadczenia zostały przeprowadzone w inkubatorze, w stałej temperaturze $+29^{\circ} \mathrm{C}$, w ciemności. Badania wykazały, że synergizm najsilniej zaznaczał się tylko w przypadku najmłodszych larw, gdzie obserwowano ponad 4-krotny spadek wartości $L C_{50}$ i LC $C_{90}$, po łącznym zastosowaniu anetolu i insektycydu. W odniesieniu do starszych larw oraz osobników dorosłych aktywność synergistyczna anetolu była bardzo słaba. Otrzymane współczynniki synergizmu wynosiły 1,05-1,26.

Słowa kluczowe: abamektyna; anetol; synergizm; olejki eteryczne; pleśniakowiec lśniący; Alphitobius diaperinus

\footnotetext{
1 Uniwersytet Mikołaja Kopernika

Wydział Biologii i Ochrony Środowiska

Lwowska 1, 87-100 Torun

${ }^{2}$ Główny Inspektorat Ochrony Roślin i Nasiennictwa

Centralne Laboratorium

Żwirki i Wigury 73, 87-100 Toruń

*corresponding author: mszczep@umk.pl
} 


\section{Wstęp / Introduction}

Nadmierna chemizacja środowiska i wynikające z niej zagrożenia skłaniają do poszukiwania alternatywnych metod ograniczania stosowania chemicznych insektycydów. Jedną z nich, prowadzącą do wzrostu toksyczności insektycydów, jest stosowanie synergetyków - substancji, które często w wyniku blokowania układów enzymatycznych owadów wpływają na procesy biotransformacji insektycydów i modyfikują ich aktywność/toksyczność. Mogą reagować z enzymami i blokować te, które biorą udział w procesie detoksykacji, głównie polisubstratowe monooksygenazy, hydrolityczne esterazy oraz transferazy, a także zwiększać przepuszczalność kutikuli i ułatwiać penetrację insektycydu do organizmu owada (Malinowski 2003). Stosowanie synergetyków pozwala na obniżenie dawek insektycydów, co powoduje mniejsze obciążenie środowiska, a także zapobiega rozwojowi odporności owadów. Synergetyki podnoszą także toksyczność insektycydów wśród populacji szkodników, u których obserwowany jest spadek wrażliwości na te powszechnie stosowane (Lambkin i Furlong 2011). Najbardziej znane synergetyki insektycydów to: butoksylan piperonylu, octan tributylocynowy, karbaryl i inne (Węgorek i wsp. 2007). Rolę synergetyków mogą spełniać także naturalne substancje pochodzenia roślinnego, jak np.: sezamina i kapsaicyna oraz komponenty olejków eterycznych, takie jak: cytronellal, $\gamma$-terpinen, estragol i inne (Silva i wsp. 2007; Abbassy i wsp. 2009; Maliszewska i Tęgowska 2012). Według Marcus i Lichtenstein (1979) składniki olejku anyżowego także wpływają na wzrost toksyczności syntetycznych insektycydów z grupy pyretroidów, karbaminianów i związków fosforoorganicznych.

Celem prowadzonych badań była ocena synergistycznego wpływu anetolu, który stanowi ponad 90\% składu olejku eterycznego pozyskanego z anyżu gwiaździstego (Illicium verum Hook. F.) (Szczepanik i Szumny 2011) na aktywność abamektyny, będącej substancją czynną insektycydu Vertimec 018 EC, wobec stadiów rozwojowych pleśniakowca lśniącego (Alphitobius diaperinus Panzer). Abamektyna z grupy makrocyklicznych laktonów, jest produktem fermentacji bakterii Streptomyces avermitilis. Jako agonista kwasu gamma-aminomasłowego zaburza funkcjonowanie układu nerwowego owadów przez zwiększony napływ jonów chloru do komórki nerwowej, jej hiperpolaryzację i zahamowanie przekazywania sygnałów (Arena i wsp. 1995). Pleśniakowiec lśniący jest szkodnikiem masowo zasiedlającym brojlernie i inne pomieszczenia inwentarskie. Jest wektorem wielu groźnych patogenów drobiu, przez co stwarza poważne problemy natury weterynaryjnej i ekonomicznej hodowcom drobiu (Axtell i Arends 1990; Ignatowicz 1998). Zwalczanie tego szkodnika jest szczególnie uciążliwe ze względu na dobrze rozwiniętą odporność behawioralną oraz wzrastającą odporność na stosowane syntetyczne insektycydy (Kaufman i wsp. 2008; Chernaki-Leffer i wsp. 2011).

\section{Materiały i metody / Materials and methods}

Doświadczenia przeprowadzono na 10- i 20-dniowych larwach oraz młodych (7-10 dniowych) chrząszczach
A. diaperinus w okresie od października 2012 do marca 2013 roku. Owady doświadczalne pochodziły z hodowli masowej prowadzonej w laboratorium zgodnie $\mathrm{z}$ metodyką opisaną przez Rice i Lambkin (2009). Jako pokarm używano roztarte $\mathrm{w}$ moździerzu granulaty paszy dla drobiu (Brojler Grower 2 Specjal - Golpasz S.A.). W badaniach zastosowano metodę żołądkową w czterch kombinacjach: (i) pokarm traktowano wzrastającymi dawkami insektycydu (wodne roztwory 0,$0125 ; 0,025 ; 0,05 ; 0,1 ; 0,15 ; 0,2$; $0,4 \%$ ); (ii) pokarm traktowano $1 \%$ acetonowym roztworem anetolu; (iii) pokarm traktowano $1 \%$ acetonowym roztworem anetolu, a następnie wzrastającymi dawkami insektycydu (działanie łączne, cumulative effect); (iiii) owady karmiono przez 3 dni pokarmem traktowanym 1\% roztworem anetolu, po czym przenoszono je na pokarm traktowany tymi samymi dawkami insektycydu (działanie następcze, subsequent effect). W próbach kontrolnych pokarm traktowano tą samą objętością wody lub acetonu. We wszystkich kombinacjach stosowano $1 \mathrm{ml}$ roztworu lub wody/1 g pokarmu. Używany w badaniach anetol pochodził z firmy Sigma-Aldrich. Śmiertelność obserwowana po 24 oraz $72 \mathrm{~h}$ korygowano stosując regułę Abbotta (Abbott 1925). Wartości LC $_{50}$ i LC $_{90}$ wyznaczono $z$ linii regresji dawka-śmiertelność. Stopień interakcji między insektycydem i anetolem wyrażono za pomocą współczynnika synergizmu (WS) wyliczonego ze wzoru (Metcalf 1967; Abbassy 2009):

$$
\mathrm{WS}=\frac{\mathrm{LC}_{50} \text { insektycydu }}{\mathrm{LC}_{50} \text { mieszaniny insektycydu i anetolu }}
$$

Wartość WS równa 1,0 wskazuje na brak oddziaływania między insektycydem $\mathrm{i}$ anetolem, wartości poniżej 1 - na działanie antagonistyczne, te powyżej 1,0 są oznaką synergizmu. Wszystkie doświadczenia przeprowadzono w stałej temperaturze $+29^{\circ} \mathrm{C}$, w 4 powtórzeniach po 10 owadów w każdej próbie.

\section{Wyniki i dyskusja / Results and discussion}

Wyniki przeprowadzonych badań wskazują na zróżnicowany wpływ anetolu na toksyczność abamektyny wobec pleśniakowca lśniącego. Wartości stężeń letalnych insektycydu wyznaczone we wszystkich wariantach doświadczeń uzależnione były od stadium rozwojowego $A$. diaperinus oraz czasu upływającego od podania ksenobiotyków. Zastosowany w badaniach anetol w $1 \%$ stężeniu nie wykazywał działania toksycznego. W jego obecności śmiertelność 10 -dniowych larw wynosiła $5-10 \%$ i była zbliżona do śmiertelności w próbach kontrolnych. Wcześniejsze badania wskazują jednak, że olejek anyżowy zastosowany w wyższych dawkach, tj. 2,5\% powoduje wysoką śmiertelność wśród młodych, 1-2 tygodniowych larw pleśniakowca lśniącego (Szczepanik i Szumny 2011). Przyczyną wyższej toksyczności olejku było niewątpliwie zastosowane wyższe stężenie. Nie można wykluczyć także synergistycznego działania pozostałych komponentów tego olejku, głównie limonenu, p-anisaldehydu czy $\gamma$-terpinenu.

Wrażliwość 10-dniowych larw na abamektynę była uzależniona od dawki i czasu. Po upływie 1 doby śmiertelność skorygowana wahała się od 2,5 do $67,5 \%$, po $72 \mathrm{~h}$ 
wzrosła do 42,5-97,5\%. Połączenie anetolu z insektycydem wpłynęło na istotny wzrost toksyczności tego ostatniego w odniesieniu do 10-dniowych larw (rys. 1a, b). $\mathrm{W}$ przypadku łącznego zastosowania insektycydu i anetolu wartości $\mathrm{LC}_{50}$ i LC $\mathrm{LC}_{90}$ wyznaczone po 24 i 72 h obniżyły się ponad 4-krotnie. Po wcześniejszym podaniu anetolu obserwowano ponad dwukrotne obniżenie wartości $\mathrm{LC}_{50}$ w ciągu 24 h. Spadek wartości LC $\mathrm{L}_{90} \mathrm{~W}$ trzecim dniu eksperymentu był niewielki i współczynnik synergizmu wynosił tylko 1,25 (tab. 1).

Wrażliwość 20-dniowych larw na abamektynę była bardzo zbliżona do tej obserwowanej wśród młodszych larw. Wartości $\mathrm{LC}_{50}$ wyznaczone po $24 \mathrm{~h}$, jak i $\mathrm{LC}_{90}$ dla obu badanych stadiów larwalnych były na tym samym poziomie, tj. około 0,3\% (tab. 1). Śmiertelność wśród larw hodowanych na diecie traktowanej samym anetolem wynosiła 10\%. Łączne podanie anetolu i insektycydu generalnie nie wpłynęło na wzrost toksyczności abamektyny wobec tego stadium larwalnego. Niemniej w ciągu 24 h obserwowano znaczne wahania w przebiegu śmiertelności larw. Szczególnie wyraźnie różnice te zaznaczały się w zakresie stężeń $0,2-0,4 \%$ (rys. 2a). Po upływie 72 h przebieg linii regresji wskazuje na słaby synergizm anetolu $\mathrm{z}$ abamektyną (rys. 2b). Współczynniki synergizmu wyznaczone dla łącznego zastosowania insektycydu i anetolu wynoszą 1,1, w przypadku działania następczego 1,26 (tab. 1).

Chrząszcze charakteryzowały się stosunkowo wysoką odpornością na abamektynę. W pierwszej dobie poziom śmiertelności owadów przy wyższych dawkach samego insektycydu był na poziomie kilkunastu procent. W próbach kontrolnych, w obecności samego anetolu oraz przy niższych dawkach insektycydu przeżywalność chrząszczy wynosiła $100 \%$ (rys. 3a). Znaczący wzrost śmiertelności obserwowano w 3. dniu eksperymentu, po zastosowaniu wyższych dawek insektycydu (rys. 3b). Wprowadzenie do diety dorosłych osobników anetolu wpłynęło na spadek ich śmiertelności. Po upływie $24 \mathrm{~h}$ od łącznego zastosowania ksenobiotyków przeżywalność chrząszczy wynosiła 100\%, co nie pozwoliło na wyznaczenie wartości $\mathrm{LC}_{50}$. W przypadku działania następczego wartość $\mathrm{LC}_{50}$ wzrosła prawie dwukrotnie (WS $=0,52$ ) i wskazuje to na działanie antagonistyczne. Po upływie $72 \mathrm{~h}$ nie obserwowano także istotnego spadku wartości $\mathrm{LC}_{90}$ po włączeniu do diety anetolu (tab. 1). Otrzymane współczynniki synergizmu wskazują na bardzo słabe oddziaływanie między abamektyną i anetolem w przypadku dorosłych osobników A. diaperinus.

Obserwowane wahania $\mathrm{w}$ synergistycznym oddziaływaniu anetolu i abamektyny mogą mieć różne podłoże. Zgodnie z wynikami badań Marcus i Lichtenstein (1979) anetol stosowany zarówno metodą kropelkową, jak i podany $\mathrm{w}$ pokarmie wpływa na wzrost toksyczności insektycydów o różnych, neurotoksycznych mechanizmach działania (blokery acetylocholinoesterazy lub kanałów sodowych) wobec muszki owocowej (Drosophila melanogaster Meigen) oraz muchy domowej (Musca domestica L.). Wydaje się więc mało prawdopodobne, aby wpływał na specyficzne enzymy związane $\mathrm{z}$ detoksykacją tylko

Tabela 1. Wpływ anetolu na wartości letalnych stężeń abamektyny dla stadiów rozwojowych $A$. diaperinus

Table 1. The effect of anethole on the lethal concentrations of abamectin for developmental stages of $A$. diaperinus

\begin{tabular}{|c|c|c|c|c|c|}
\hline \multirow{3}{*}{$\begin{array}{l}\text { Stadium rozwojowe } \\
\text { Developmental stage }\end{array}$} & \multirow{3}{*}{$\begin{array}{c}\text { Insektycyd }+\mathrm{A} / \text { metoda aplikacji } \\
\text { Insecticide }+\mathrm{A} / \text { application method }\end{array}$} & \multicolumn{4}{|c|}{$\begin{array}{l}\text { Czas żerowania } \\
\text { Feeding time }\end{array}$} \\
\hline & & \multicolumn{2}{|c|}{$24 \mathrm{~h}$} & \multicolumn{2}{|c|}{$72 \mathrm{~h}$} \\
\hline & & $\mathrm{LC}_{50}[\%]$ & WS & $\mathrm{LC}_{90}[\%]$ & WS \\
\hline \multirow[t]{3}{*}{$\begin{array}{l}\text { Larwy } 10 \text {-dniowe } \\
\text { 10-day old larvae }\end{array}$} & Vertimec 018 EC & 0,32 & - & 0,30 & - \\
\hline & $\begin{array}{l}\text { Vertimec } 018 \mathrm{EC}+\mathrm{A} / \text { działanie łączne } \\
\text { Vertimec } 018 \mathrm{EC}+\mathrm{A} / \text { cumulative effect }\end{array}$ & 0,07 & 4,47 & 0,07 & 4,29 \\
\hline & $\begin{array}{l}\text { Vertimec } 018 \mathrm{EC}+\mathrm{A} / \text { działanie następcze } \\
\text { Vertimec } 018 \mathrm{EC}+\mathrm{A} / \text { subsequent effect }\end{array}$ & 0,15 & 2,13 & 0,25 & 1,25 \\
\hline \multirow[t]{3}{*}{$\begin{array}{l}\text { Larwy } 20 \text {-dniowe } \\
\text { 20-day old larvae }\end{array}$} & Vertimec 018 EC & 0,37 & - & 0,32 & - \\
\hline & $\begin{array}{l}\text { Vertimec } 018 \mathrm{EC}+\mathrm{A} / \text { działanie łączne } \\
\text { Vertimec } 018 \mathrm{EC}+\mathrm{A} / \text { cumulative effect }\end{array}$ & 0,31 & 1,19 & 0,29 & 1,10 \\
\hline & $\begin{array}{l}\text { Vertimec } 018 \mathrm{EC}+\mathrm{A} / \text { działanie następcze } \\
\text { Vertimec } 018 \mathrm{EC}+\mathrm{A} / \text { subsequent effect }\end{array}$ & 0,48 & 0,77 & 0,26 & 1,26 \\
\hline \multirow[t]{3}{*}{$\begin{array}{l}\text { Chrząszcze } \\
\text { Adults }\end{array}$} & Vertimec 018 EC & 1,34 & - & 0,42 & - \\
\hline & $\begin{array}{l}\text { Vertimec } 018 \mathrm{EC}+\mathrm{A} / \text { działanie łączne } \\
\text { Vertimec } 018 \mathrm{EC}+\mathrm{A} / \text { cumulative effect }\end{array}$ & - & - & 0,40 & 1,05 \\
\hline & $\begin{array}{l}\text { Vertimec } 018 \mathrm{EC}+\mathrm{A} / \text { działanie następcze } \\
\text { Vertimec } 018 \mathrm{EC}+\mathrm{A} / \text { subsequent effect }\end{array}$ & 2,56 & 0,52 & 0,37 & 1,14 \\
\hline
\end{tabular}

A - anetol - anethole, WS - współczynnik synergizmu - synergism ratio 

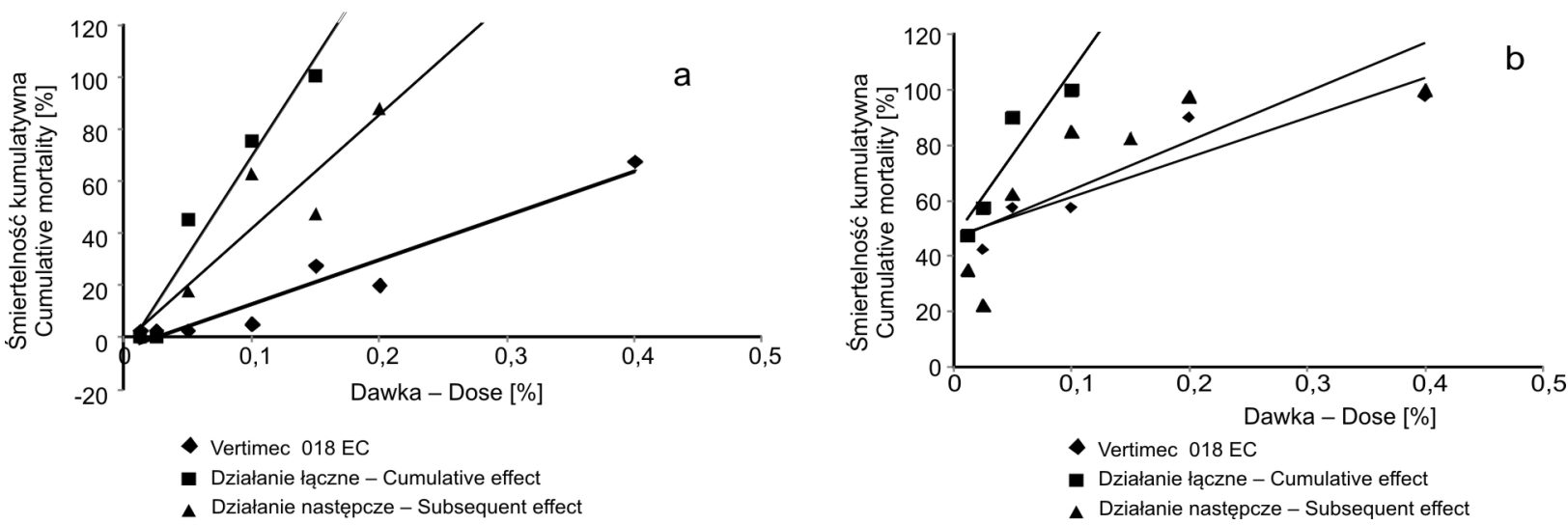

Rys. 1. Wpływ anetolu na aktywność abamektyny wobec 10-dniowych larw A. diaperinus. a - po $24 \mathrm{~h} ; \mathrm{b}-$ po $72 \mathrm{~h}$

Fig. 1. Effect of anethole on the abamectin activity against 10-day old larvae of A. diaperinus. $\mathrm{a}-\mathrm{after} 24 \mathrm{~h} ; \mathrm{b}-\mathrm{after} 72 \mathrm{~h}$
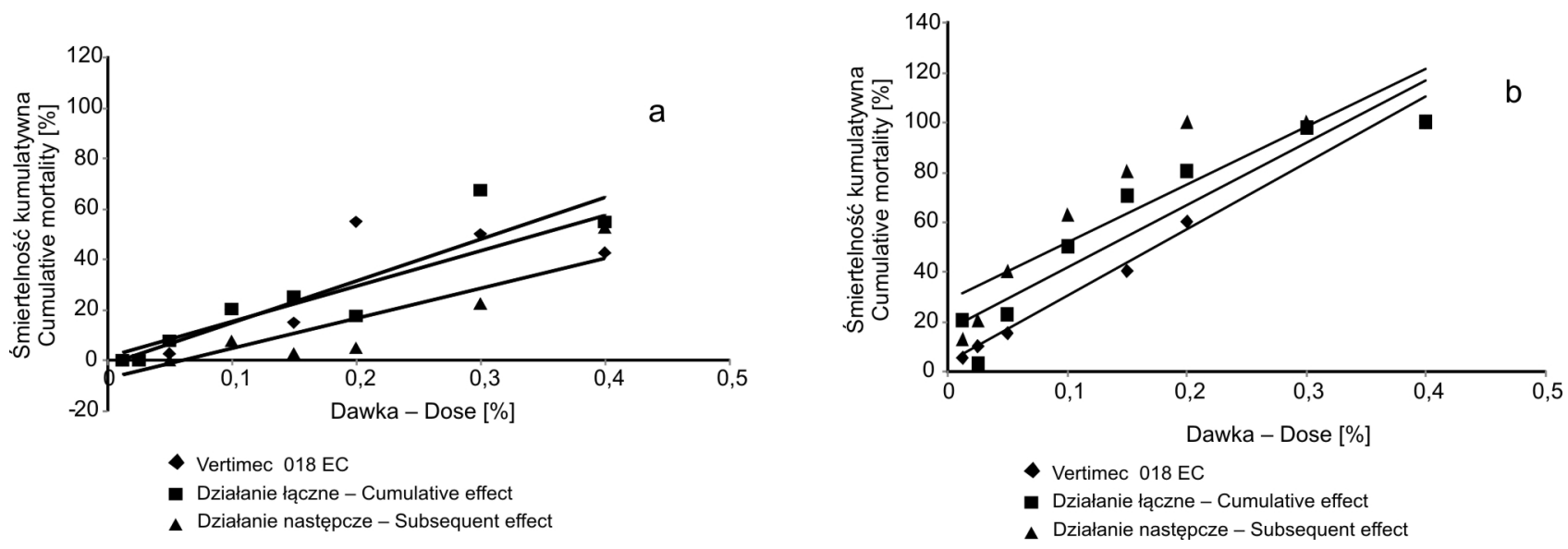

Rys. 2. Wpływ anetolu na aktywność abamektyny wobec 20-dniowych larw A. diaperinus. a - po $24 \mathrm{~h} ; \mathrm{b}-$ po $72 \mathrm{~h}$

Fig. 2. Effect of anethole on the abamectin activity against 20-day old larvae of A. diaperinus. a - after $24 \mathrm{~h} ; \mathrm{b}-\mathrm{after} 72 \mathrm{~h}$
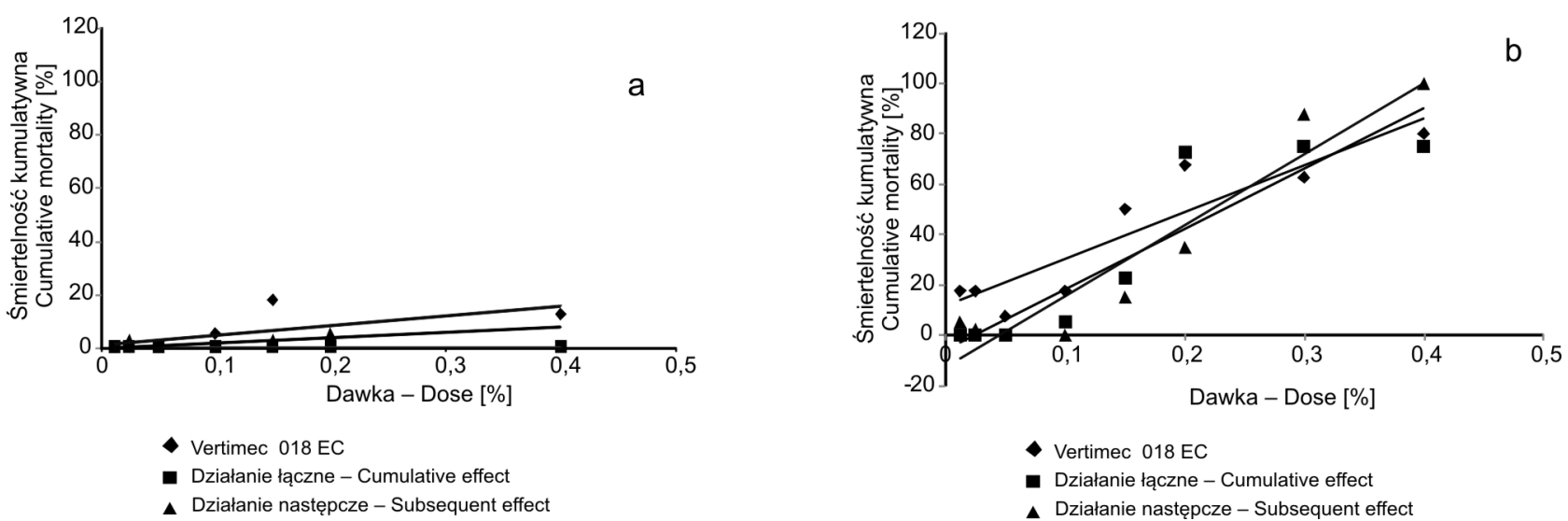

Rys. 3. Wpływ anetolu na aktywność abamektyny wobec chrząszczy A. diaperinus. a - po $24 \mathrm{~h} ; \mathrm{b}-$ po $72 \mathrm{~h}$

Fig. 3. Effect of anethole on the abamectin activity against adults of A. diaperinus. a - after $24 \mathrm{~h} ; \mathrm{b}-\operatorname{after} 72 \mathrm{~h}$

wybranych insektycydów. Zakres jego aktywności może mieć znacznie szerszy zasięg, podobnie jak wiele innych substancji pochodzenia roślinnego może synergizować insektycydy o określonym mechanizmie działania. Synergistyczną aktywność w odniesieniu do insektycydu blokującego acetylocholinoesterazę (Profenofos) wykazuje też $\gamma$-terpinen wyizolowany z olejku majerankowego (Abbassy i wsp. 2009). Współczynnik synergizmu w przypadku drugiego stadium larwalnego sówki bawełnówki (Spodoptera littoralis Boisduval) wynosi 2,53. Łączne zastosowanie karbaminianu (methomyl) $\mathrm{z} \gamma$-terpinenem powoduje znaczny wzrost toksyczności insektycydu wobec mszycy 
burakowej (Aphis fabae Scopoli) (współczynnik synergizmu 3,88). Anetol podany metodą kropelkową zwiększa także penetrację insektycydów do wnętrza organizmu owadów. Ten sam mechanizm może być związany z szybszą penetracją przez błonę perytroficzną i docieraniem do hemolimfy po zastosowaniu metody żołądkowej.

Aktywność synergistyczna anetolu związana jest także z zastosowaną dawką. Wzrastające, ale wciąż subletalne dawki tego związku powodują wzrost toksyczności paraoksonu wobec M. domestica (Marcus i Lichtenstein 1979). Słabsza aktywność synergistyczna wobec starszych stadiów rozwojowych $A$. diaperinus może wynikać także $\mathrm{z}$ zastosowanej w badaniach dawki. W przeliczeniu na $1 \mathrm{~g}$ masy ciała larw 10-dniowych jest ona wyższa niż u larw 20-dniowych i osobników dorosłych. Nie można wykluczyć też lepiej rozwiniętych mechanizmów detoksykacji u starszych osobników. Zjawisko wyższej wrażliwości młodszych stadiów rozwojowych owadów na insektycydy oraz olejki eteryczne i ich komponenty jest powszechnie obserwowane. Na przykład drugie stadium larwalne Chilo partellus (Swinhoe), groźnego szkodnika kukurydzy wymaga 20-krotnie wyższej dawki tymolu niż pierwsze stadium dla osiągnięcia tego samego poziomu śmiertelności (Singh i wsp. 2010). Wrażliwość larw trojszyka gryzącego (Tribolim castaneum Herbst) oraz pleśniakowca lśniącego na anetol i tymol spada wraz z wiekiem (Mondal i Khalequzzaman 2010; Szczepanik i Szumny 2011; Szczepanik i wsp. 2012).

Przedstawiony na przykładzie pleśniakowca lśniącego synergizujący wpływ anetolu na aktywność abamektyny można rozpatrywać $w$ szerszych kategoriach, także pod kątem zwalczania szkodników upraw. Preparat Vertimec 018 EC o działaniu kontaktowym i żołądkowym, przeznaczony jest do zwalczania przędziorków i owadów szkodli- wych na roślinach warzywnych i ozdobnych pod osłonami. Zastosowanie tego insektycydu na wczesne stadia rozwojowe szkodników łącznie $\mathrm{z}$ anetolem być może przyczyniłoby się do znacznego obniżenia jego dawek. Anetol jako główny składnik atraktantu zachodniej korzeniowej stonki kukurydzianej (Diabrotica virgifera Le Conte) (Kołodziejczyk 2003) może również wpłynąć na wzrost poziomu żerowania owadów i przyczynić się do pobierania większej ilości traktowanego pokarmu, a wraz z nim insektycydów stosowanych do zwalczania tego szkodnika. Hipotezy te wymagają jednak dalszych, szczegółowych badań.

\section{Wnioski / Conclusions}

1. Anetol zastosowany jako synergetyk wpływa na wzrost toksyczności abamektyny wobec 10-dniowych larw pleśniakowca lśniącego.

2. W odniesieniu do starszych stadiów larwalnych oraz osobników dorosłych $A$. diaperinus nie obserwowano istotnego wzrostu toksyczności abamektyny po zastosowaniu anetolu jako synergetyka.

3. Łączne zastosowanie 1\% roztworu anetolu z abamektyną powoduje silniejszą redukcję wczesnych stadiów rozwojowych $A$. diaperinus przy niższych dawkach insektycydu.

Projekt został sfinansowany przez Uniwersytet Mikołaja Kopernika w Toruniu w ramach grantu badawczego Uniwersytetu Mikołaja Kopernika nr 502-B/2013.

\section{Literatura / References}

Abbassy M.A., Abdelgaleil S.A.M., Rabie R.Y.A. 2009. Insecticidal and synergistic effects of Majorana hortensis essential oil and some of its major constituents. Entomologia Experimentalis et Applicata 131:225-232.

Abbott W.S. 1925. A method for computing the effectiveness of an insecticide. Journal of Economic Entomology 18: $265-267$.

Arena J.P., Liu K.K., Paress P.S., Frazier E.G., Cully D.F., Mrozik H., Schaeffer J.M. 1995. The mechanism of action of avermectins in Caenorhabditis elegans: correlation between activation of glutamate-sensitive chloride current, membrane binding, and biological activity. Journal of Parasitology 81: 286-294.

Axtell R.C., Arends J.J. 1990. Ecology and management of arthropod pests of poultry. Annual Review of Entomology 35: 101-126.

Chernaki-Leffer A.M., Sosa-Gomez D.R., Almeida L.M., Lopes I.O.N. 2011. Susceptibility of Alphitobius diaperinus (Panzer) (Coleoptera, Tenebrionidae) to cypermethrin, dichlorvos and triflumuron in southern Brazil. Revista Brasileira de Entomologia 55: $125-128$.

Ignatowicz S. 1998. Nowoczesny program zwalczania much, pleśniakowca lśniącego i innych szkodliwych owadów w zabudowaniach inwentarskich. Życie Weterynaryjne 8: 304-306.

Kaufman P.E., Strong C., Rutz D.A. 2008. Susceptibility of lesser mealworm (Coleoptera: Tenebrionidae) adults and larvae exposed to two commercial insecticides on unpainted plywood panels. Pest Management Science 64: 108-111.

Kołodziejczyk A. 2003. Naturalne związki organiczne. PWN, Warszawa, 601 ss.

Lambkin T.A., Furlong M.J. 2011. Metabolic mechanisms only partially explain resistance to pyrethroids in Australian broiler house populations of lesser mealworm (Coleoptera: Tenebrionidae). Journal of Economic Entomology 104 (2): 629-635.

Malinowski H. 2003. Odporność owadów na insektycydy. Mechanizmy powstawania i możliwości przeciwdziałania. Wieś Jutra, Warszawa, $211 \mathrm{ss}$

Maliszewska J., Tęgowska E. 2012. Capsaicin as an organophosphate synergist against Colorado potato beetle (Leptinotarsa decemlineata Say). Journal of Plant Protection Research 52 (1): 28-34.

Marcus C., Lichtenstein E.P. 1979. Biologically active components of anise: Toxicity and interactions with insecticides in insects. Journal of Agricultural and Food Chemistry 27 (6): 1217-1223.

Metcalf R.L. 1967. Mode of action of insecticide synergists. Annual Review of Entomology 12: 229-256. 
Mondal M., Khalequzzaman M. 2010. Toxicity of naturally occurring compounds of plant essential oil against Tribolium castaneum (Herbst). Journal of Biological Sciences 10: 10-17.

Rice S.J., Lambkin T.A. 2009. A new culture method for lesser mealworm, Alphitobius diaperinus. Journal of Applied Entomology 133: $67-72$.

Silva G.S., Michels M.G., Toma S.B., Terra F.E., Soares V.E., Costa A.J. 2007. Effectiveness of the compound chlorpyrifos + cypermethrin + citronellal against Alphitobius diaperinus. Laboratory analysis and residue determination in carcasses. Revista Brasileira de Ciência Avícola 9 (3): 157-160.

Singh R., Koul O., Rup P.J., Jindal J. 2010. Evaluation of dietary toxicity of some essential oil allelochemicals for the management of Chilo partellus (Swinhoe). Journal of Plant Protection Research 50 (3): 293-301.

Szczepanik M., Szumny A. 2011. Insecticidal activity of star anise (Illicum verum Hook. F.) fruits extracts against lesser mealworm, Alphitobius diaperinus Panzer (Coleoptera: Tenebrionidae). Allelopathy Journal 27 (2): 277-288.

Szczepanik M., Zawitowska B., Szumny A. 2012. Insecticidal activities of Thymus vulgaris essential oil and its components (thymol and carvacrol) against larvae of lesser mealworm, Alphitobius diaperinus Panzer (Coleoptera: Tenebrionidae). Allelopathy Journal 30 (1): 129-142.

Węgorek P., Obrępalska-Stęplowska A., Nowaczyk K., Zamojska J. 2007. Poziom odporności polskich populacji słodyszka rzepakowego (Meligethes aeneus F.) na pyretroidy; mechanizmy odporności w świetle badań molekularnych. [The level of resistance of polish populations of Pollen beetle (Meligethes aeneus F.) against pyrethroids: mechanisms of rseistance in light of molecular research]. Progress in Plant Protection/Postępy w Ochronie Roślin 47 (1): 383-388. 